\title{
NILAI DIAGNOSTIK ULTRASONOGRAFI DOPPLER DALAM MENENTUKAN KEGANASAN TUMOR OVARIUM DIBANDINGKAN HASIL HISTOPATOLOGI
}

\author{
THE DIAGNOSTIC VALUE OF DOPPLER ULTRASOUND \\ IN DETERMINING THE MALIGNANCY OF OVARIAN TUMOR \\ COMPARED WITH RESULT OF HISTOPATOLOGY
}

\author{
Nurhayati $^{1}{ }^{*}$, Mirna Muis ${ }^{1}$, Muhammad Ilyas ${ }^{1}$ \\ Departemen Radiologi, Fakultas Kedokteran, Universitas Hasanuddin, \\ Jalan Perintis Kemerdekaan Km.10, Makassar, Indonesia
}

\begin{abstract}
ABSTRAK
Kanker ovarium merupakan keganasan organ viseral dan paling mematikan serta dianggap silent killer. Ultrasonografi (USG) Doppler adalah teknik pencitraan yang sering digunakan, noninvasif dan biaya relatif murah dalam menentukan keganasan tumor ovarium. Penggunaan USG Doppler dimungkinkan untuk menilai vaskularisasi tumor dan nilai resistive index. Penelitian ini bertujuan mengetahui nilai diagnostik USG Doppler dalam menentukan keganasan tumor ovarium dibandingkan hasil histopatologi. Penelitian ini dilaksanakan di Bagian Radiologi RS. Dr. Wahidin Sudirohusodo dan RS. Universitas Hasanuddin, Makassar dimulai pada bulan Juni-Agustus 2018. Metode penelitian bersifat cross sectional dengan desain uji diagnostik. Sebanyak 55 sampel dengan klinis tumor ovarium umur 14-67 tahun dilakukan pemeriksaan USG Doppler untuk menilai distribusi vaskuler, jumlah vaskuler, dan nilai resistive index, dilanjutkan sistem kategori untuk menentukan sifat tumor jinak atau ganas. Ganas, jika terdapat $\geq 2$ kriteria Doppler ganas, dan jinak jika terdapat $<2$ kriteria Doppler ganas. Hasil diagnosis USG Doppler dibandingkan dengan hasil histopatologi. Analisis statistik yang dilakukan berdasarkan skala pengukuran yaitu uji chi-square, sensitifitas, spesifisitas, nilai prediksi positif, nilai prediksi negatif dan akurasi, kurva ROC serta nilai diagnostik USG Doppler dapat ditentukan dengan hasil histopatologi sebagai standar baku. Hasil penelitian ini menunjukkan USG Doppler memiliki nilai diagnostik yang cukup tinggi dalam menilai keganasan tumor ovarium dengan sensitivitas $94,7 \%$, spesifisitas $70,6 \%$, nilai prediksi positif $87,8 \%$, nilai prediksi negatif $85,7 \%$ dan akurasi $87,2 \%$.

Kata kunci : histopatologi, tumor ovarium, USG doppler,
\end{abstract}




\section{ABSTRACT}

Ovarian cancer is a visceral organ malignancy that is lethal and is considered as "silent killer". Doppler US is a technique that is non-invasive, and relatively cheap in determining the malignancy ovarian tumor. This examination may assessed tumor vascularization and resistive index. This study aimed to investigate the diagnostic values of Doppler Ultrasound in determining the malignancy of ovarian tumor compared with result of histopathology. This study was conducted in Radiology Department of Dr.Wahidin Sudirohusodo Hospital and Hasanuddin University Hospital, Makassar from June through August 2018. It used the cross sectional diagnostic test study method. Doppler Ultrasound examination was carried on 55 samples with clinical sign of ovarian tumor aged between 14-67 years to evaluate the vascular distribution, number of vascular, and values of resistive index; followed by categorical system to determine the characteristics of benign or malignant ovarian tumor. The lesion is considered malignant if two or more Doppler malignant criteria were found, and benign if less than two criteria were found. The result of Doppler was compared to the result of histopathology. The statistical analysis was conducted by using chi-square test, sensitivity, spesivicity, positive predictive value, negative predictive value, and accuracy, ROC curve and diagnostic value of Doppler Ultrasound were determine based on the histopatological result as a standard. This study result showed that Doppler Ultrasound had diagnostic value which was high enough to evaluate tumor malignancy with sensitivity of $94.7 \%$, specificity of $70.6 \%$, positive predictive value of $87.8 \%$, negative predictive value of $85.7 \%$, and the accuracy of $87.2 \%$.

\section{Keywords: doppler ultrasound, histopathology, ovarian tumor,}

\section{Penulis korespondensi:}

Nurhayati

Departemen Radiologi, Fakultas Kedokteran, Universitas Hasanuddin

Jl.Perintis Kemerdekaan Km. 10, Makassar, 90245

Email : nurhayatimutia4@gmail.com

\section{PENDAHULUAN}

Kanker ovarium adalah kumpulan tumor dengan histogenesis yang beraneka ragam dari indung telur, dapat berasal dari ketiga dermoblast ( ektodermal, endodermal, dan mesodermal) dengan sifta-sifat histologi maupun biologi yang beraneka ragam. Kanker ovarium merupakan keganasan organ viseral dan paling mematikan serta dianggap silent killer wanita saat ini. Kanker ovarium menjadi kanker kedua terbanyak pada wanita setelah kanker uterus, tetapi sebagai penyebab kematian terbanyak dibandingkan kanker serviks dan kanker korpus. Di dunia, angka insiden kanker ovarium pada tahun 2008 adalah 9.4\%. Di Amerika Serikat kanker ovarium merupakan penyebab kematian utama dari semua kanker ginekologik. Pada tahun 2007 terdapat 22.430 kasus baru keganasan ovarium dengan angka kematian yang mencapai kurang lebih 15.280 wanita setiap tahun. (Committee on Gynecologic Practice, 2011; Ferlay et al., 2008; Jemal et al., 2011). 
Kanker ovarium umumnya baru menimbulkan keluhan bila telah menyebar ke rongga peritoneum atau organ visera lainnya. Pada tingkat ini penyakit telah mencapai stadium lanjut, sehingga tindakan pembedahan dan terapi adjuvan seringkali tidak menolong. Kurangnya gejala awal maupun sensitifitas skrining serta teknik deteksi dini kanker ovarium yang sulit merupakan alasan mengapa umumnya saat ditemukan telah berada pada stadium lanjut. Pengenalan dini kanker ovarium stadium awal berdasarkan pemeriksaan fisik saja tidak cukup, sehingga perlu dilengkapi pemeriksaan lain seperti ultrasonografi (USG), computerized tomography (CT) Scan, magnetic resonance imaging (MRI) dan petanda tumor (Jung et al., 2002; Kim, 2004 ; Berek, 2006).

Diagnosis tumor ovarium dapat dilakukan Radiologi, karena memiliki alat-alat yang cukup banyak, seperti USG, CT Scan, MRI dan kedokteran nuklir. USG tanpa diragukan lagi adalah teknik pencitraan diagnostik yang paling sering digunakan, noninvasif dengan biaya yang relatif murah (Sadek, 2006).

Terdapat banyak tipe tumor berasal dari ovarium. Sekitar $80 \%$ tumor ovarium adalah jinak dan banyak dialami pada wanita usia 20-45 tahun, sedangkan sisanya adalah ganas yang terjadi pada wanita usia lebih tua, yaitu 45-60 tahun. Pada tumor ovarium jinak, penderita dapat diterapi dengan sukses melalui pembedahan, mengangkat satu atau bagian dari ovarium yang mengandung tumor. Tumor ovarium ganas dan sudah mengalami metastasis memerlukan penanganan yang lebih kompleks (Sadek, 2006).

USG Color Doppler telah menjadi metode baru. Pada beberapa penelitian, pencitraan aliran Color Doppler dan Pulse Doppler merupakan metode yang berguna untuk membedakan massa ovarium yang jinak dengan yang ganas. Penggunaan USG Color Doppler dimungkinkan untuk menilai vaskularisasi tumor. Meskipun penggunaannya masih kontroversial, tapi laporan meta-analisis menunjukkan bahwa penggunaan tambahan USG Color Doppler dapat menurunkan tingkat positif palsu dari hasil evaluasi morfologi tumor. Gambaran tumor ovarium yang hipervaskuler, vaskuler di sentral dan nilai Resistive Index (RI) yang rendah merupakan prediktor keganasan ovarium pada USG Doppler. Penetapan nilai cut off Resistive Index yang rendah berbeda-beda pada beberapa penelitian.

Buy et al., pada tahun 1995 melakukan penelitian untuk mengevaluasi pentingnya Doppler warna (colour Doppler) dikombinasikan dengan sonografi konvensional dalam mengkarakterisasi massa ovarium jinak dan ganas dan untuk membandingkan hasilnya dengan analisis spectral Doppler saja dan sonografi konvensional saja. Hasil penelitian didapatkan dengan menggunakan sonografi konvensional saja, akurasi 83\%, sensitivitas 88\%, dan spesifisitas 82\%. Menggunakan sonografi konvensional dan Color Doppler, akurasi 95\%, sensitivitas 88\%, dan spesifisitas 97\%. Dengan menggunakan analisis spectral Doppler, yaitu ganas jika $\mathrm{RI} \leq 0,4$, ketepatannya adalah $77 \%$, sensitivitasnya $18 \%$, dan spesifisitasnya $98 \%$. Menambahkan Color Doppler ke sonografi konvensional menghasilkan spesifisitas dan nilai prediktif positif yang lebih tinggi dari pada sonografi konvensional saja. Spesifisitas meningkat dari $82 \%$ menjadi $97 \%$ ( $<<0.001$ ), dan nilai prediksi positif meningkat dari $63 \%$ menjadi $91 \%$. (Buy et al., 1995).

Penentuan sifat tumor ovarium yang jinak atau ganas menggunakan USG Doppler sendiri tanpa dikombinasi dengan USG Gray-Scale sebagai prediktor malignansi pre operatif masih dalam perdebatan para peneliti. Pada dasarnya, gambaran morfologi tumor ovarium berdasarkan USG berkorelasi dengan gambaran makroskopik berdasarkan hasil histopatologi. Korelasi ini telah dibuktikan dengan baik. Namun, pada kebanyakan kasus, akibat variasi ekstrim karakteristik makroskopik tumor ovarium membuat sulit menegakkan diagnosis histologi yang 
tepat dari gambaran USG. Selain itu, teknik USG Doppler sangat tergantung operator, sehingga pengalaman pemeriksa sangat mempengaruhi hasil yang diperoleh dalam hal sensitifitas dan spesifitas. Hasil histopatologi digunakan sebagai gold standard dengan menggunakan teknik standar yaitu pemotongan paravin ataupun potong beku (frozen section) yang telah lama digunakan dan telah diterima kesesuainnya untuk digunakan dalam klinis termasuk kelainan ginekologi. Pada keseluruhan neoplastik, pada umunya tumor jinak lebih banyak ditemukan (93,78\% dibandingkan tumor ganas $(4,14 \%)$ dan tumor borderline sekitar 2,07 \%. (Sadek, 2006; Busmar, 2006; Moka et al., 2007; Gupta and Jain, 2016; Sing et al., 2017; Ayhan and Ozler, 2016; Pranab, 2018).

Tujuan penelitian ini adalah untuk menentukan nilai diagnostik USG Doppler dalam menentukan keganasan tumor ovarium dibandingkan hasil histopatologi sebagai gold standar.

\section{METODE PENELITIAN}

Penelitian ini menggunakan metode cross sectional dengan desain uji diagnostik untuk mengetahui nilai diagnostik USG Doppler dalam menentukan keganasan tumor ovarium dibandingkan hasil histopatologi. Populasi sampel penelitian adalah semua pasien yang dikirim ke Bagian Radiologi Rumah Sakit Dr. Wahidin Sudirohusodo dan Rumah Sakit Universitas Hasanuddin Makassar untuk dilakukan pemeriksaan USG Doppler dengan klinis tumor ovarium dari bulan Juni-Agustus 2018. Sampel adalah populasi terjangkau yang memenuhi kriteria inklusi. Pengambilan sampel dilakukan dengan cara consecutive sampling yaitu semua pasien yang memenuhi kriteria dimasukkan dalam penelitian sampai besar sampel yang dibutuhkan terpenuhi.

\section{Jalannya Penelitian}

Metode pengumpulan data adalah semua pasien yang memenuhi kriteria inklusi dan menandatangani informed concent menjalani pemeriksaan USG Doppler dengan menggunakan transduser curve 3,5 MHz meliputi USG Color Doppler untuk menilai jumlah vaskuler (hipervaskuler-ganas, avaskuler/hipovaskuler-jinak), distribusi vaskuler (vaskuler di sentral dan septa-ganas, vaskuler di perifer-jinak) dan USG Spectral Doppler untuk mengukur Resistive Index (RI) dengan formula PSV-EDV/PSV (RI $\leq 0,475$-ganas, RI $>0.475$-jinak) yang sebelumnya dievaluasi awal dengan USG Gray Scale. Penentuan tumor jinak/ganas ovarium berdasarkan sistem kategori. Prediksi ganas jika terdapat $\geq 2$ kriteria Doppler ganas, dan prediksi jinak jika terdapat $<2$ kriteria Doppler ganas. Untuk menghindari bias dalam pengukuran ataupun dalam penentuan tumor jinak atau ganas, maka akan dilakukan penilaian oleh peneliti dan observer. Observer adalah konsulen di bagian Radiologi. Selanjutnya menunggu hasil pemeriksaan histopatologi dari Bagian Patologi Anatomi. Hasil penelitian dicatat dalam lembaran format penelitian kemudian dilakukan analisis data dan hasilnya disajikan dalam bentuk narasi, tabel dan grafik.

\section{Analisis Data}

Analisis data terdiri dari analisis deskriptif dilakukan untuk melihat karakteristik distribusi jumlah dan persentase berdasarkan demografi (umur, status menikah, status menopause, dan jumlah paritas), distribusi vaskuler, jumlah vaskuler, dan nilai resistive index berdasarkan pemeriksaan USG Doppler, dan distribusi kategori hasil pemeriksaan histopatologi. Analisis bivariat menggunakan uji Chi-Square. Uji diagnostik digunakan untuk mengetahui nilai sensitivitas, spesifisitas, nilai prediksi positif, nilai prediksi negatif, dan akurasi. Pengolahan data statistik berdasarkan uji diagnostik yaitu menilai sensitivitas, spesifisitas, nilai prediksi positif, 
nilai prediksi negatif, dan akurasi dengan menggunakan tabel $2 \times 2$. Pengolahan data dengan menggunakan software Statistical Programme Social Science (SPSS). Kurva ROC untuk menilai cut-off nilai Resistive Index (RI) .

Penelitian ini telah mendapat persetujuan etik dari Komite Etik Penelitian Kedokteran, Fakultas Kedokteran Universitas Hasanuddin dengan nomor : 526/H4.8.4.5.31/PP36KOMETIK/2018.

\section{HASIL DAN PEMBAHASAN}

Dari 100 pasien yang diperiksa, sebanyak 55 sampel yang memenuhi kriteria inklusi dengan rentang umur 14-67 tahun, dan sebanyak 45 sampel diekslusi karena tidak dilakukan operasi dan pemeriksaan histopatologi serta hasil histopatologi yang tidak representatif.

Tabel I. Distribusi sampel berdasarkan demografi

\begin{tabular}{lccc}
\hline & Kategori & Jumlah (n) & Persentase (\%) \\
\hline Umur (Tahun) & $<20$ & 3 & 5,5 \\
& $20-45$ & 25 & 45,5 \\
\multirow{3}{*}{ Status Menikah } & $>45$ & 27 & 49,1 \\
& Belum & 12 & 21.8 \\
Status Menopause & Sudah & 43 & 78,2 \\
& Belum & 30 & 54,5 \\
Jumlah Paritas & Sudah & 25 & 45,5 \\
& 0 & 23 & 41,8 \\
& $1-2$ & 15 & 27,3 \\
& $>2$ & 17 & 30,9 \\
\hline Total & & 55 & 100 \\
\hline
\end{tabular}

Sumber : Data Primer

Tabel I memperlihatkan distribusi sampel berdasarkan demografi. Hasil didapatkan kelompok umur yang paling banyak menderita tumor ovarium adalah umur $>45$ tahun sebanyak 27 sampel (49,1\%), umur 20-45 tahun sebanyak 25 sampel $(45,5 \%)$ dan dibawah 20 tahun sebanyak 3 sampel (5,5\%). Umur termuda adalah 14 tahun, dan umur tertua 67 tahun, dengan rerata umur 43 tahun.

Berdasarkan status menikah, tumor ovarium didapatkan lebih banyak pada kelompok yang sudah menikah sebanyak 43 sampel $(78,2 \%)$, sedangkan yang belum menikah 12 sampel $(21,8 \%)$. Berdasarkan status menopause, sampel terbanyak didapatkan pada perempuan yang belum menopause sebanyak 30 sampel $(54,5 \%)$ dan 25 sampel $(45,5 \%)$ pada perempuan yang sudah menopause. Berdasarkan jumlah paritas, terbanyak didapatkan 23 sampel $(41,8 \%)$ pada perempuan yang tidak memiliki paritas, 15 sampel (27,3\%) pada paritas 1-2, dan 17 sampel $(30,9 \%)$ pada paritas yang lebih banyak $>2$. 
Tabel II. Distribusi sampel berdasarkan kategori hasil pemeriksaan histopatologi

\begin{tabular}{lcc}
\hline $\begin{array}{l}\text { Hasil pemeriksaan histopatologi } \\
\text { tumor ovarium }\end{array}$ & $\mathbf{n}$ & $\boldsymbol{\%}$ \\
\hline Ganas & 38 & 69,1 \\
Jinak & 17 & 30,9 \\
\hline Total & 55 & 100,0 \\
\hline
\end{tabular}

Sumber : Data Primer

Tabel II menunjukkan distribusi sampel berdasarkan hasil pemeriksaan histopatologi. Sebanyak 55 sampel yang diperoleh, didapatkan 38 sampel $(69,1 \%)$ adalah ganas dan 17 sampel $(30,9 \%)$ adalah jinak. Hal ini berbeda dengan penelitian Sing et al., (2017) yang menyatakan bahwa dari keseluruhan neoplastik, pada umumnya tumor jinak lebih banyak ditemukan $(93,78 \%)$ dibandingkan tumor ganas $(4,14 \%)$ begitupula dengan penelitian Gupta and Jain (2016), menemukan 22,9\% tumor ganas dan 72,9\% tumor ovarium jinak.

Tabel III. Hubungan antara kriteria demografi dengan tumor ovarium berdasarkan hasil histopatologi

\begin{tabular}{lccccc}
\hline \multicolumn{1}{c}{ Kriteria } & Kategori & \multicolumn{3}{c}{ Hasil histopatologi } & $*$ \\
\hline Status & & & Ganas & Jinak & \\
menikah & Belum menikah & $\mathrm{n}$ & 9 & 3 & \\
& & $\%$ & $(75,0 \%)$ & $(25 \%)$ & $p=0,735$ \\
& Menikah & $\mathrm{n}$ & 29 & 14 & \\
& & $\%$ & $(67,4 \%)$ & $(32,6 \%)$ & \\
\hline Status & Menopause & $\mathrm{N}$ & 18 & 7 & \\
Menopause & & $\%$ & $(72 \%)$ & $(28 \%)$ & \\
& \multirow{2}{*}{ Belum menopause } & $\mathrm{n}$ & 20 & 10 & $p=0,894$ \\
& & $\%$ & $(66,7 \%)$ & $(33,3 \%)$ & \\
Jumlah paritas & 0 & $\mathrm{~N}$ & 17 & 6 & \\
& & $\%$ & $(73.9 \%)$ & $(26,1 \%)$ & \\
& \multirow{2}{*}{$1-2$} & $\mathrm{n}$ & 10 & 5 & \\
& & $\%$ & $(66,7 \%)$ & $(33,3 \%)$ & $p=0,801$ \\
& $>2$ & $\mathrm{n}$ & 11 & 6 & \\
\hline Umur (Tahun) & $<20$ & $\mathrm{~N}$ & $(64,7 \%)$ & $(35,3 \%)$ & \\
& & $\%$ & $(100 \%)$ & $(0,0)$ & \\
& $20-45$ & $\mathrm{n}$ & 15 & 10 & $\mathrm{p}=0,269$ \\
& & $\%$ & $(60 \%)$ & $40 \%$ & \\
& $>45$ & $\mathrm{n}$ & 20 & 7 & \\
& & $\%$ & $(74,1 \%)$ & $(25,9 \%)$ & \\
& & & & \\
& & & &
\end{tabular}

Sumber : Data primer. Keterangan : * uji Chi-square, $p<0,00$ 
Pada tabel III, distribusi demografi yang dihubungkan dengan hasil pemeriksaan histopatologik didapatkan bahwa tumor ganas ovarium paling banyak didapatkan pada perempuan yang sudah menikah sebanyak 29 sampel $(67,4 \%)$ dan tumor jinak juga didapatkan yang terbanyak pada perempuan dengan status belum menikah terdapat 12 total sampel menderita tumor ganas, 9 sampel $(75,5 \%)$ terbukti ganas, dan 3 sampel $(25 \%)$ ternyata jinak. Dari 43 total sampel tumor jinak pada penderita yang sudah menikah terdapat 14 sampel $(32,6 \%)$ terbukti jinak, dan 29 sampel $(67,4 \%)$ ternyata ganas. Uji Chi-square menunjukkan hubungan yang tidak bermakna antara status menikah dengan tingkat keganasan tumor ovarium dengan nilai $p=0,735(p>0,05)$. Hal ini tidak sejalan dengan penelitian Barlett (2000), Pabengari (2014) bahwa perempuan yang belum menikah cenderung menderita tumor ganas ovarium lebih tinggi dibandingkan yang sudah menikah.

Berdasarkan status menopause, terdapat 25 total sampel dikatakan ganas, dengan 18 sampel (72\%) terbukti ganas, dan 7 sampel (28\%) ternyata jinak. Yang belum menopuse didiagnosis tumor jinak total 30 sampel dengan 10 sampel $(33,3 \%)$ terbukti jinak, dan 20 sampel $(66,7 \%)$ ternyata ganas, dengan hasil uji chi-square, $\mathrm{p}=0,894(p>0,05)$ yang berarti tidak ada hubungan bermakna antara status menopause dengan tingkat keganasan tumor ovarium berdasarkan hasil histopatologi. Penelitian ini tidak sejalan dengan penelitian sebelumnya (Barlett, 2000; Pabengari, 2014).

Berdasarkan jumlah paritas, pada tumor ovarium dengan paritas 0 terbukti ganas sebanyak 17 sampel $(73,9 \%)$ dan terdapat 6 sampel $(26,1 \%)$ yang ternyata jinak dari total sampel 23 ganas. Dari jumlah paritas 1-2, didapatkan 10 sampel (66,7\%) ganas, 5 sampel jinak $(33,3 \%)$, dan paritas >2 didapatkan 6 sampel (35\%) terbukti jinak, dan 11 sampel $(64,7 \%)$ ternyata ganas. Dari hasil uji chi-square di dapatkan nilai $\mathrm{p}=0,801(\mathrm{p}>0,05)$ artinya tidak terdapat hubungan bermakna antara jumlah paritas dengan keganasan tumor ovarium. Penelitian ini tidak sejalan dengan penelitian sebelumnya Barlett (2000) dan Pabengari (2014) yang menyatakan tingginya kasus tumor ovarium pada paritas 0 dan rendahnya kasus pada paritas banyak

Berdasarkan kelompok umur, terdapat 3 sampel (100\%) yang dikatakan ganas dan terbukti ganas juga pada hasil histopatologi. Sedangkan umur 20-45 tahun didapatkan 25 total sampel ganas dengan 15 sampel (60\%) terbukti ganas dan 10 sampel $(10 \%)$ terbukti jinak. Sementara umur > 45 tahun terdapat 27 sampel, dengan 20 sampel $(74,1 \%)$ adalah ganas dan 7 sampel $(25,9 \%)$ adalah jinak. Nilai $\mathrm{p}=0,269 \%$ artinya tidak terdapat hubungan yang bermakna antara umur dengan keganasan tumor ovarium. Berdasarkan jumlah paritas, pada tumor ovarium dengan paritas 0 terbukti ganas sebanyak 17 sampel $(73,9 \%)$ dan terdapat 6 sampel $(26,1 \%)$ yang ternyata jinak dari total sampel 23 ganas. Dari jumlah paritas 1-2, didapatkan 10 sampel $(66,7 \%)$ ganas, 5 sampel jinak (33,3\%), dan paritas >2 didapatkan 6 sampel (35\%) terbukti jinak, dan 11 sampel $(64,7 \%)$ ternyata ganas. Dari hasil uji Chi square di dapatkan nilai $\mathrm{p}=0,801$ $(p>0,05)$ artinya tidak terdapat hubungan bermakna antara jumlah paritas dengan keganasan tumor ovarium.

Berdasarkan kelompok umur, terdapat 3 sampel (100\%) yang dikatakan ganas dan terbukti ganas juga pada hasil histopatologi. Sedangkan umur 20-45 tahun didapatkan 25 total sampel ganas dengan 15 sampel (60\%) terbukti ganas dan 10 sampel (10\%) terbukti jinak. Sementara umur > 45 tahun terdapat 27 sampel, dengan 20 sampel $(74,1 \%)$ adalah ganas dan 7 sampel $(25,9 \%)$ adalah jinak. Nilai $p=0,269$ artinya tidak terdapat hubungan yang bermakna antara umur dengan keganasan tumor ovarium. Hal ini tidak sesuai dengan penelitian Barlett (2000) yang mendapatkan hasil tumor ovarium ganas pada wanita usia tua yaitu 45-60 tahun, dan jinak umur 20-45 tahun, angka kejadian tumor ganas lebih banyak pada perempuan sudah 
menopause, status belum menikah dan jumlah paritas sedikit atau tidak ada, sedangkan jinak sebaliknya.

Tabel IV. Distribusi sampel berdasarkan distribusi vaskuler, jumlah vaskuler dan nilai resistive index pada pemeriksaan USG Doppler

\begin{tabular}{|c|c|c|c|}
\hline \multicolumn{2}{|c|}{ Kategori } & \multirow{2}{*}{$\frac{\mathbf{n}}{41}$} & \multirow{2}{*}{$\frac{\%}{74,5}$} \\
\hline Distribusi vaskuler & Sentral & & \\
\hline & Septa & 3 & 5,5 \\
\hline & Perifer & 9 & 16,4 \\
\hline & Tidak ada & 2 & 3,6 \\
\hline \multirow[t]{3}{*}{ Jumlah vaskuler } & Hipervaskuler & 43 & 78,2 \\
\hline & Hipovaskuler & 10 & 18,2 \\
\hline & Avaskuler & 2 & 3,6 \\
\hline \multirow[t]{2}{*}{ Resistive Index } & $<=0,475$ & 39 & 70,9 \\
\hline & $>0,475$ & 16 & 29,1 \\
\hline
\end{tabular}

Sumber : Data Primer

Pada tabel IV, distribusi sampel penelitian berdasarkan pemeriksaan USG Doppler meliputi distribusi vaskuler, jumlah vaskuler dan nilai resistive indeks. Untuk distribusi vaskuler, didapatkan 41 sampel $(74,5 \%)$ di sentral (komponen solid ataupun proyeksi papiler), 3 sampel $(5,5 \%)$ di septa, 9 sampel $(16,4 \%)$ di perifer, 2 sampel $(3,6 \%)$ tidak ditemukan vaskularisasi. Distribusi jumlah vaskuler berdasarkan USG Doppler, didapatkan tumor yang hipervaskuler sebanyak 43 sampel (78,2\%), hipovaskuler 10 sampel (18,2\%), dan avaskuler sebanyak 2 sampel (3,6\%). Distribusi sampel berdasarkan nilai Resistive Index (RI), didapatkan 39 sampel (70,9\%) mempunyai $\mathrm{RI} \leq 0,475$ dan 16 sampel mempunyai nilai $\mathrm{RI}>0,475$.

Berdasarkan USG Doppler, tumor jinak ovarium umumnya didapatkan distribusi vaskuler di perifer/ di dinding tumor, atau peritumoral, sementara tumor ganas ovarium vaskularisasi di sentral (komponen solid/proyeksi papiler dan septanya). Berdasarkan jumlah vaskuler, tumor jinak ovarium umumnya didapatkan avaskuler hingga hipovaskuler, sementara tumor ganas ovarium umumnya hipervaskuler. Hal ini sesuai dengan penelitian Abbas et al., 2014; Timmerman et al., 2006). Berdasarkan nilai RI, tumor jinak ovarium memiliki nilai RI yang tinggi $>0,475$, dan tumor ganas nilai RI rendah $\leq 0,475$. Pada USG Spectral Doppler, nilai RI dihitung berdasarkan rumus PSV-EDV/PSV. Aliran arteri dikarakteristikkan oleh kecepatan aliran bifasik dengan komponen sistol dan diastol. (Salem et al., 2016; Ahvad et al., 2010; Hassan et al., 2014; Bhargava, 2010)

Pada analisis ROC, didapatkan Area Under Curve (AUC) Resistive Index dengan kejadian tumor ovarium berdasarkan hasil pemeriksaan histopatologi adalah 0,706 yang berarti bahwa rata-rata sensitivitas untuk semua nilai spesifisitas yang mungkin adalah sedang.

Untuk nilai RI, didapatkan cut-off yang berbeda-beda pada beberapa peneilitian dalam penentuan tumor jinak ovarium atau ganas. Pada penelitian Abbas et al., 2014, Malhotra and Talafdar, 2016) didapatkan nilai $\mathrm{RI} \leq 0,42$ adalah ganas, dan $\mathrm{RI}>0,42$ adalah jinak. Menurut Caruso (1996), mendapatkan nilai cut-off RI 0,43. Sedangkan menurut Fawsia et al., (2010) nilai cut-off RI <0,5 curiga ganas, RI >0,5 curiga jinak dengan sensitivitas 91,7\%, spesifisitas 88,9\%, dan akurasi $90 \%$, nilai prediksi positif $84,6 \%$, nilai prediksi negatif $94,1 \%$. Berikut grafik terlampir pada Gambar 1. 


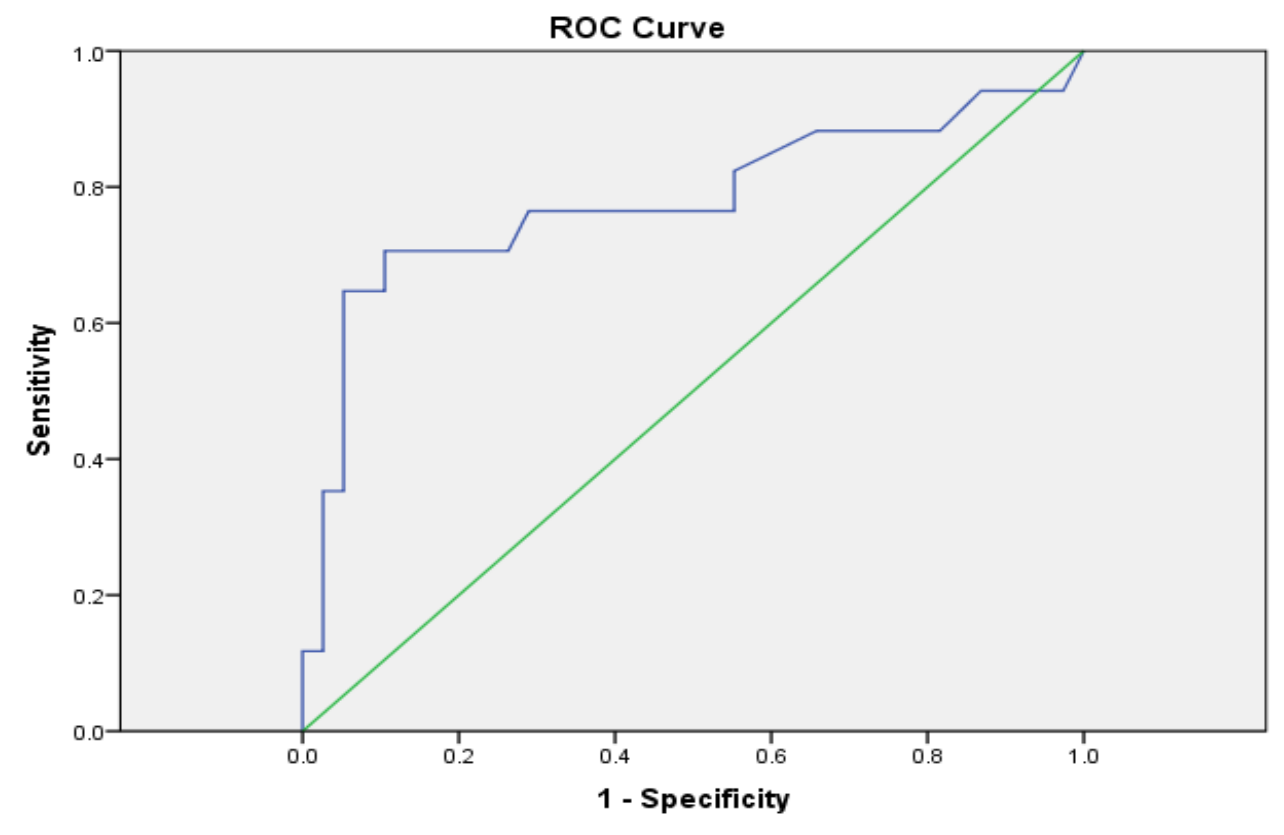

Diagonal segments are produced by ties.

Gambar 1. Kurva ROC nilai resistive index dibandingkan dengan hasil pemeriksaan histopatologi

Angiogenesis merupakan proses onkogenesis. Formasi pembuluh-pembuluh darah baru menyebabkan terjadinya neovaskularisasi yang merupakan awal dari neoplasia. Rendahnya resistensi pada pembuluh darah yang berlokasi di sentral merupakan respon terhadap aktifitas angiogenik tumor. Pembuluh darah di sentral tumor memiliki lapisan otot polos yang lebih tipis sehingga mempunyai resistensi aliran yang lebih rendah dan dapat menerima aliran darah yang lebih banyak bila dibandingkan pembuluh darah yang memiliki resistensi yang tinggi. (Kurjak et al., 1994)

Tabel V. Distribusi sampel berdasarkan kombinasi variabel USG Doppler

\begin{tabular}{lcc}
\hline Hasil USG Doppler & N & \% \\
\hline Ganas & 41 & 74,5 \\
Jinak & 14 & 25,5 \\
\hline Total & 55 & 100 \\
\hline
\end{tabular}

\section{Sumber : Data Primer}

Pada Tabel V menunjukkan distribusi sampel berdasarkan kombinasi ketiga kriteria USG Doppler. Dari 55 total sampel didapatkan 41 sampel $(74,5 \%)$ tumor ovarium ganas dengan kriteria Doppler ganas $\geq 2$, dan tumor ovarium jinak dengan kriteria Doppler ganas < 2 sebanyak 14 sampel $(25,5 \%)$. 
Tabel VI. Nilai diagnostik berdasarkan kombinasi variabel USG Doppler abdomen dengan hasil pemeriksaan histopatologi

\begin{tabular}{lccc}
\hline USG Doppler abdomen & \multicolumn{3}{c}{ Hasil Histopatologi } \\
\hline & Ganas $(\mathbf{n})$ & Jinak $(\mathbf{n})$ & Total \\
\hline Ganas & 36 & 5 & 41 \\
Jinak & 2 & 12 & 14 \\
\hline Total & 38 & 17 & 55 \\
\hline
\end{tabular}

Sumber: Data Primer

Pada tabel VI, dari 55 sampel, sebanyak 41 sampel yang didiagnosis ganas, terbukti ganas oleh histopatologi sebanyak 36 sampel $(87,8 \%)$ dan sisanya ada 3 sampel terbukti jinak $(12,2 \%)$. Dari 14 sampel yang dibaca jinak oleh histopatologi, terbukti jinak 12 sampel $(85,7 \%)$ dan terbukti ganas 2 sampel (14,3\%). Penentuan tumor jinak atau ganas berdasarkan sistem kategori. Kategori jinak adalah tumor dengan kriteria USG Doppler ganas < 2, sedangkan kelompok ganas adalah tumor dengan kriteria $\geq 2$ USG Doppler ganas. Berdasarkan hasil uji diagnostik didapatkan sensitivitas USG Doppler adalah 94,7\%, spesifisitas 70,6 \%, nilai prediksi positif $87,8 \%$, nilai prediksi negatif $85,7 \%$, dan akurasi $87,2 \%$. Hasil penelitian ini tidak jauh berbeda dengan penelitian Choudary et al., (2012) USG Doppler memiliki sensitivitas 83,3\%, spesifisitas $88,9 \%$, nilai prediksi positif 90,9\%, nilai prediksi negatif 93,3\%, dan akurasi 92,3\%.

Manfaat dari penelitian ini adalah memberikan informasi ilmiah mengenai nilai diagnostik USG Doppler sebagai modalitas radiologi noninvasif untuk membedakan tumor ovarium jinak atau ganas prabedah, modalitas ini sangat membantu klinisi dalam menentukan tindakan yang cepat dan tepat pada penderita tumor ovarium sehingga dapat mengurangi tingkat morbiditas dan mortalitas. Kesulitan pada penelitian ini adalah memerlukan pengalaman, ketelitian, dan kemampuan operator dalam melakukan pengukuran Resistive Index (RI) karena vaskularisasi tumor merupakan struktur yang kecil sehingga memerlukan ketelitian.

\section{KESIMPULAN}

USG Doppler dapat digunakan sebagai alat diagnostik dalam menentukan keganasan tumor ovarium dengan nilai diagnostik yang cukup tinggi yaitu sensitivitas $94,7 \%$, spesifisitas $70,6 \%$, nilai prediksi positif $87,8 \%$, nilai prediksi negatif $85,7 \%$, dan akurasi $85,7 \%$.

\section{UCAPAN TERIMA KASIH}

Terima kasih kepada Departemen Radiologi RSUP Dr. Wahidin Sudirohusodo dan RS Univeristas Hasanuddin Makassar yang sudah memberikan kesempatan bagi peneliti untuk melakukan pengambilan data penelitian.

\section{DAFTAR PUSTAKA}

Abbas, A.M., Zahran, K.M. 2014. A new scoring model for characterization of adnexal masses based on two-dimensional gray-scale and colour Doppler sonographic features. FVV in ObGyn 6(2): 68-74.

Avhad, A., Lakhar, D.L., Kachewar, S.G., Chaudari, M. 2016. Role of ultrasonography and colour doppler in the evaluation of gynecological pelvic mass. Scholars Journal of Applied Medical science (SJAMS) 4(10B): 3654-3664. 
Ayhan, A., and Ozler, A. 2016. Potential role of increasing number of section in frozen section diagnosis of ovarian tumors. J Exp Ther Oncol 11(4): 245-50.

Barlett, J.M.S. 2000. Ovarian cancer methods and protocols. Totowa-New Jersey. Humana press Inc.

Bhargava, S.K. 2010. Textbook of color doppler imaging. $2^{\text {nd }}$ Edition. New Delhi Jaypee Brothers Medical Publishers (P). Ltd.

Buy, J., Michel, A., Ghossaini., Dani, K.C ., Sciot. 1995. Characterization of Adnexal Masses: Combination of Color Doppler and Conventional Sonography Compared with Spectral Doppler Analysis Alone and Conventional Sonography Alone. American Roentgen Ray Society.

Busmar, B. 2006. Kanker Ovarium. Dalam : Aziz, M.F., Andrijono \& Saifuddin, A.B. (ed) Buku Acuan Nasional Onkologi Ginekologi. Ed.1. Jakarta. Yayasan Bina Pustaka Sarwono Prawirodiharjo.

Committee on Gynecologic Practise. 2011. The role of the obstetrician-gynecologist in the early detection of epithelial ovarian cancer. ACOG Committee Opinion No. 477. Obstet Gynecol 117: 742-6.

Choudary, G., Boparai, A., Singh, G. 2012. Role of combining colour doppler and gray scale ultrasound in characterizing adnexal masses. Journal of Family and Reproductive Health 6: 43-47.

Fawsia, H., Karim, M.N., Rahman, S.M., Nasren, K. 2010. Preoperative detection of ovarian cancer by color doppler ultrasonography and CA 125. Bangladesh Med Res Counc Bull 36: 68-73.

Ferlay, J., Shin, H.R., Bray, F., Forman, D., Mathers, C. 2008. Globocan v1.2. Cancer incidence and mortality worldwide. IARC Cancer base No. 10 (Internet) Lyon, france : International Agency for Research on Cancer.

Gupta, K.P., and Jain, S.K. 2016. Role of ultrasonography and color doppler to diagnosis of pelvic massess and its correlation with histopatological finding. International Journal of Scientific Study 4(3): 147-153.

Hassan, A.Y., Ellatif, A.A., Darweesh, F.F. 2014. Two dimensional ultrasound and doppler in assessment of adnexal masses in correlation to hystopatological analysis. Academic Journal of Cancer Reasearch 7(1): 08-18.

Jemal, A., Bray, F., Center, M.M., Ferlay, J., Ward, E., Forman D. 2011. Global Cancer statistics. CA Cancer J Clin 61: 69-90. 
Jung, S.E., Lee, J.M., Rha, S.E., Byun, J.Y., Jung, J.I., and Hahn, S.T. 2002. CT, and MRI Imaging of Ovarian Tumors with Emphasis on Differential Diagnosis. Radiographics 22(6): $1305-1325$.

Kim, K.A. 2004. Benign Ovarian Tumors with Solid and Cystic Component that mimic Malignancy. American Journal Radiology 182(5): 1259-1265.

Kurjak, A., Shalan, A., Kupesik, S. 1994. Ultrasonic Characterization of adnexal masses. Departement of obstetric and Gynecology, Medical school University of Zagreb.

Malhotra, A. Tarafdar, S. 2016. Benign versus malignant adnexal masses: Does addition of Color and Spectral Doppler over and above the Gray-scale Ultrasonography improves diagnostic.

Moka, S.C., Welchc, W.R., Samimid, G. 2007.Etiology and pathogenesis of Epithelial Ovarian Cancer Disease Markers. Gynecol Oncol 23. 367-376.

Pabengari, A. 2014. Akurasi Ultrasonografi ransabdominal dalam menilai malignitas tumor ovarium. Konsentrasi Pendidikan Dokter Spesialis Terpadu Program Studi Biomedik Program Pascasarjana Universitas Hasanuddin, Makassar.

Pranab, D. 2018. Frozen Section: Principle and Procedure. Basic and Advanced Laboratory Techniques in Histopatology and Cytology. pp 51-55.

Sadek, S.M. 2006. Evaluation of a new scoring system to differentiate benign from malignant adnexal masses in comparison with other scoring system. Zagaziq University faculty of medicine.

Salem, F. M, et al. 2016. Imaging modalities in differentiating of various adnexal lessions. Departement of Radiodiagnosis and Medical Imaging.

Singh, M., Jaka, K.K., Kafle, S.U. 2017. Histopatologycal analysis of neeoplastic and nonneoplastic lesion of ovary : a 4 year study in Eeastern Nepal. Birat Journal of Healt Sciences 2 .

Timmerman, D., Valentin, L., Bourne, T.H., Collin, W.P., Verlest, H., Vargote, I. 2006. International Ovarian Tumor Analysis (IOTA) group. Terms, defenition and measurement to describe the sonographic feature adnexal tumors: a consensus opinion from the International Ovarian Tumor Analisys (IOTA) Group. Ultrasound obstet Gynecol. 